\title{
Томаты на юге
}

Т.В. Чернова, В.В. Огнев, Е.И. Корсунов

Дан анализ значения овощных культур на примере томата на юге России. Показан вклад Агрохолдинга «Поиск» в создание сортимента томата для юга России. Определены перспективы создания новых отечественных гибридов томата с высокими потребительскими качествами.

Ключевые слова: овощи, томат, селекция, сортимент, технологии, импортозамещение.

вощеводство в России - это одна из самых динамично развивающихся отраслей. По признанию специалистов [1], наблюдающийся рост валового производства овощей на юге России обусловлен в первую очередь увеличением урожайности за счет освоения передовых технологий и новых сортов и гибридов. Юг России считается основным регионом, где сосредоточено производство ранних и теплолюбивых овощей. Значителен вклад региона и в переработку овощного сырья. Здесь производятся основные объемы консервированных овощей $[2,10]$. Объективно овощеводство России может играть серьезную роль в мировом производстве овощей, особенно с учетом возможности производства экологически чистой и безопасной продукции [2].

Важную роль в повышении эффективности отечественного овощеводства играет селекция и семеноводство. В мире только отдельные высокоразвитые страны и инноваци-

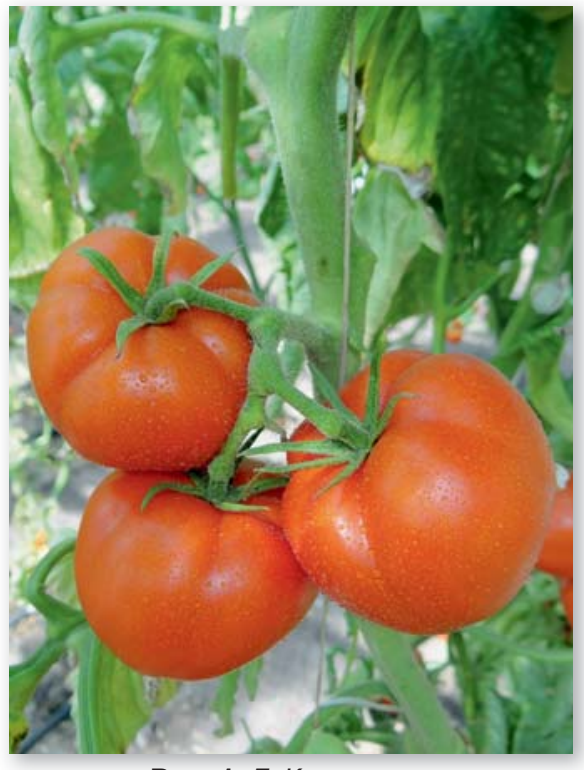

Рис. 1. $F_{1}$ Краснодон онноориентированные компании занимаются селекцией. А ведь эти отрасли несут, в числе прочего, и такую базисную функцию, как определение продовольственной независимости государства - создание, сохранение и распространение ценных генетических ресурсов [3]. Именно биологический потенциал сорта - основной фактор наращивания объемов производства, повышения качества продукции и снижения ее себестоимости. Однако здесь важно не только создание новых сортов и гибридов, но и дальнейшее их научное сопровождение при освоении в производстве. Только отдельные компании, в числе которых и Агрохолдинг «Поиск», занимаются подобной работой [4].

Одна из ведущих культур в овощном производстве на юге России томат. Его широко возделывают во всех категориях хозяйств, в открытом и защищенном грунте [5]. Среди других культур томат выделяется своим богатым химическим составом и воз-

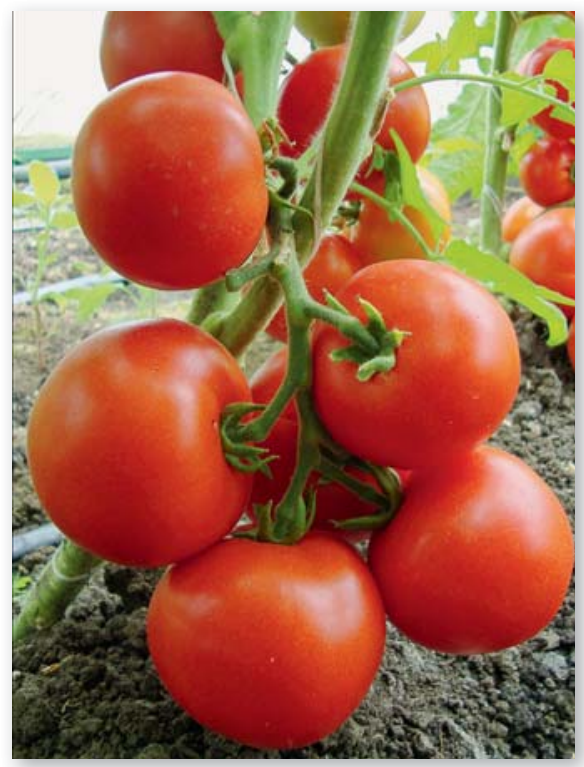

Рис. 2. $F_{1}$ Бобрин можностью его дальнейшего совершенствования. Его употребляют в пищу в свежем виде, в различных консервах и используют как ценную добавку к мясным, рыбным и овощным блюдам. Томат улучшает их усвояемость, питательную и лечебную ценность [6, 10]. Биологическая ценность, химический состав и полезные качества плодов томата очень изменчивы. Немаловажную роль при этом играют генетические особенности сортов и гибридов, технологии их возделывания, способы использования и культура потребления [7].

Основная цель исследований анализ состояния производства плодов томата на юге России, существующих при этом проблем и выработка мер по их решению, определению стратегии и направлений отечественной селекции томата для юга России.

Отечественной селекции с большим трудом приходится отвоевывать рынок у иностранных компаний, занявших его в кризисные девяностые годы XX века. Основная заслуга в этом принадлежит частным селекционно-семеноводческим компаниям. Анализ рынка томата, выращиваемого в защищенном грунте, показывает, что в условиях санкционного давления Запада объем собственного производства в 2017 году вырос на 26,6\%

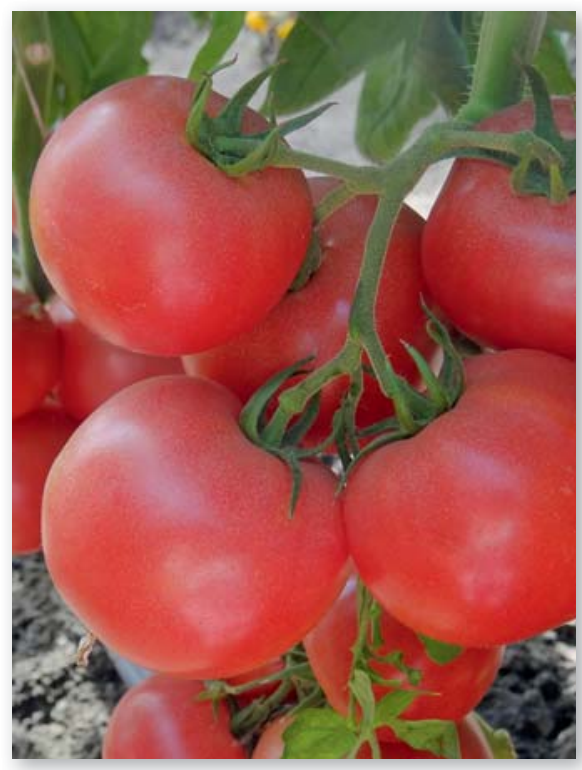

Рис. 3. $F_{1}$ Персиановский 
по отношению к 2016 году, но одновременно вырос и импорт за счет новых экспортеров и возобновления поставок ранних томатов из Турции. Не произошло полного самообеспечения России тепличными томатами, хотя и наблюдается явный прогресс в этом. В 2012 году самообеспечение составило $17,0 \%$, в 2015 году - 24,9\%, в 2017 году уже $39,5 \%$, а в 2018 году - 41,0\% [8]. Аналогично обстоят дела и с томатами из открытого грунта, где самообеспеченность достигается за счет натурального хозяйства, когда более $75 \%$ томата производится в личных подсобных хозяйствах населения. В сельхозпредприятиях отмечается перемещение товарного производства в отдельные зоны и концентрация его там, где наблюдается избыток трудовых ресурсов и более благоприятные почвенно-климатические условия. Здесь определились своего рода лидеры. Интенсивно наращивает объемы производства томата из открытого грунта Республика Дагестан. Развивают производство и переработку Астраханская и Волгоградская области при снижении посевных площадей и валового сбора в Краснодарском крае и Ростовской области. Последняя продолжает лидировать в развитии производства томата в весенних теплицах. Неоднозначная ситуация с производством томата и в Республике Крым [9]. Определенные сложности возникают у товаропроизводителей в обеспечении реализации продукции. Слабое развитие логистики и со-

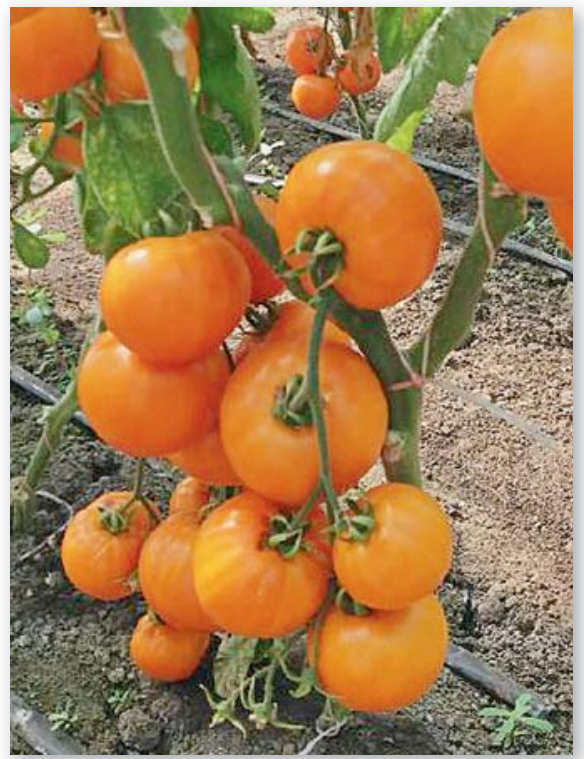

Рис. 4. Перспективный желтоплодный гибрид ответствующей инфраструктуры по формированию товарных партий при сильной дифференциации производства, отсутствие необходимых объемов хранилищ, мощностей по переработке, сортировке, упаковке продукции при растущем спросе становится главным тормозом в росте производства и потребления томата в России.

Вместе с тем растет спрос на современные высокопродуктивные гибриды томата для открытого и защищенного грунта. Уровень отечественной селекции томата, в том числе в ведущих селекционно-семеноводческих компаниях, прежде всего в Агрохолдинге «Поиск», достаточно высок, чтобы выдерживать конкуренцию с иностранными компаниями, особенно в нынешней экономической ситуации, когда важным является оптимальное соотношение цены и качества продукции. Освоение в производстве того или иного сорта имеет свою цену. В эту цену включаются как собственно затраты на создание нового генотипа, так и издержки на его продвижение и реализацию. И если затраты на селекцию в российских компаниях заведомо ниже, чем у их конкурентов с Запада, то система продвижения, рекламы товара находится еще не на должном уровне. Она уступает и по качеству, и по агрессивности, и по эффективности в целом. Относительно нормальная ситуация складывается с реализацией семян. Здесь у частных российских компаний есть отлаженная система доработки, фасовки, сертификации качества семян, созда-

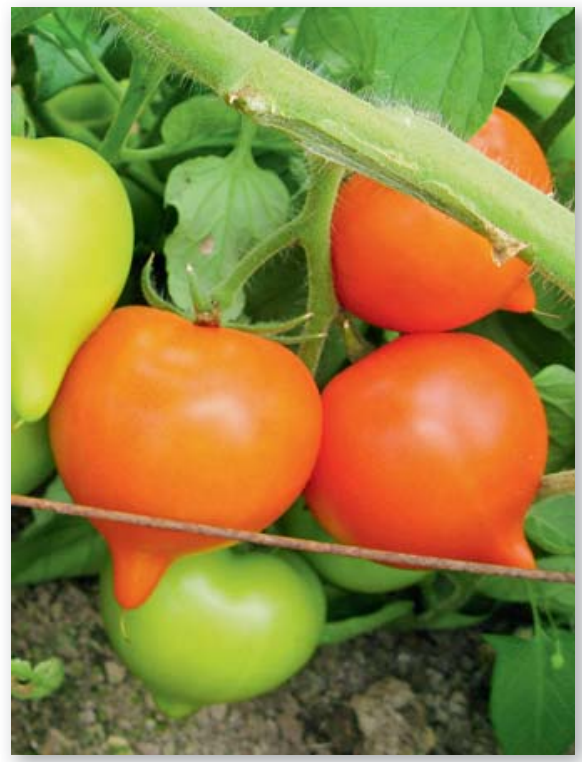

Рис. 5. $F_{1}$ Донской ны и успешно функционируют дилерские сети. Существуют проблемы и в отечественной агротехнологической науке.

Таким образом, при создании достаточно качественного сортимента, проблемой в отечественном импортозамещении является слабое научное сопровождение новых сортов и гибридов. И это касается как информационной составляющей, так и разработки соответствующих технологий возделывания на базе современных систем питания, технического и технологического прогресса в производстве товарной продукции. Этот пробел вынуждены за свой счет решать те же селекционно-семеноводческие компании. Естественно, что импортные удобрения, средства защиты, технические средства, прежде всего сопровождают импортные же сорта и гибриды. Только совсем недавно отечественные компании освоили доработку семян, уже принятую во всем мире,- это инкрустация, дражирование, покраска, фасовка калиброванных семян поштучно, протравливание и другие прецизионные технологии. Что же касается создания и освоения инновационных удобрений, средств защиты растений, техники и технологий, то они по большей части импортные и зависимость в отрасли от них приближается к 90-100\%. Особого прогресса в этой части не наблюдается, кроме биологических средств защиты, отдельных видов удобрений и средств химической защиты, но и их производство и освоение находятся не на должном уровне.

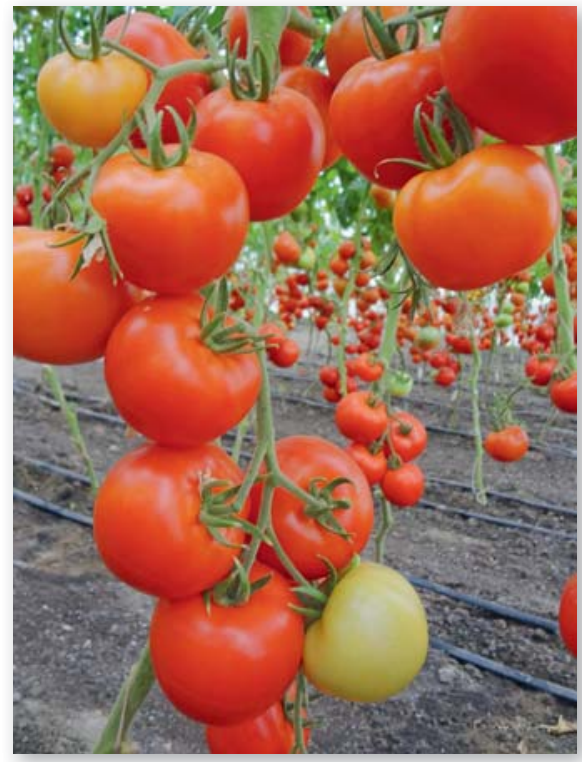

Рис. 6. $F$, Пламенный 
Южный селекционный центр Агрохолдинга «Поиск» занимается созданием сортимента томата для открытого грунта и весенних теплиц, стремясь удовлетворить потребности населения в качественной продукции для местного потребления, вывоза в промышленные центры средней полосы, различных видов переработки на томатопродукты и для цельноплодного консервирования. Не упускается из вида и создание т.н. эксклюзивных сортов и гибридов для мелкотоварного производства.

Учитывая изменение спроса, селекционные программы постоянно корректируются. Это позволяет вовремя обеспечить возникающую потребность в продукции с новым качеством. Для потребления в свежем виде в местах производства и вывоза в промышленные центры создан ряд гибридов томата с различными характеристиками. Из красноплодных гибридов для открытого грунта отметим уже включенные в Государственный реестр селекционных достижений гибриды с детерминантным типом роста $F_{1}$ Краснодон (рис. 1), $F_{1}$ Бобрин (рис. 2) и ряд перспективных новинок - Гибриды 7/17, 8/17 и 1/18. Новые гибриды отличаются яркой окраской, сохраняющейся при высоких температурах, устойчивостью к растрескиванию, имеющих повышенную лежкость и транспортабельность. Из розовоплодных гибридов предлагаются товаропроизводителям гибриды $F_{1}$ Легионер и $\mathrm{F}_{1}$ Персиановский (рис. 3). Они также устойчивы к растрескиванию

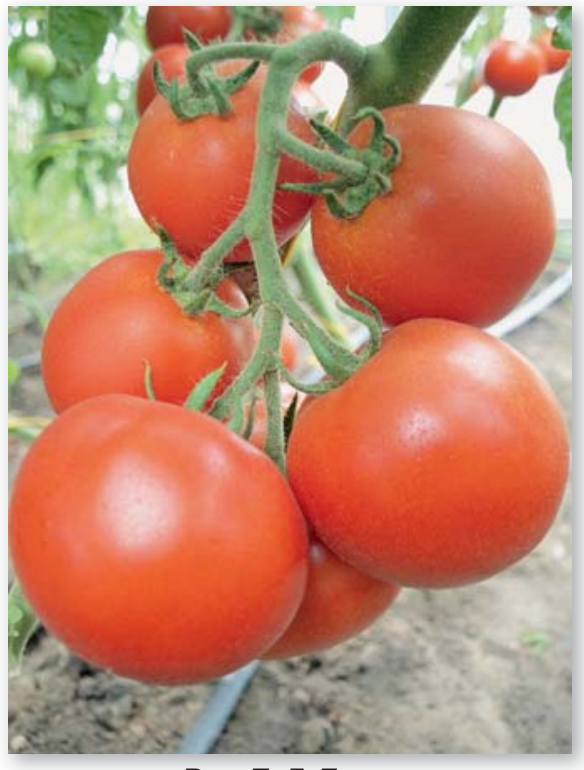

Рис. 7. $F_{1}$ Пегас и пригодны не только для потребления в свежем виде, но и для перевозки на большие расстояния. В ближайшей перспективе появятся на рынке и желтоплодные гибриды (рис. 4), а в недалеком будущем - и гибриды с темно-фиолетовыми плодами типа Кумато. Это также будут гибриды для коммерческого производства, отличающиеся высокой урожайностью и товарностью, устойчивостью к наиболее вредоносным болезням и комплексу неблагоприятных факторов среды, что присуще всем нашим гибридам.

Для весенних теплиц созданы гибриды как детерминантные, так и индетерминантные с укороченными междоузлиями. Эти гибриды можно выращивать как в коротких весенне-летнем и летне-осеннем оборотах, так и в продленном весенне-летнем обороте. Из красноплодных на юге России хорошо себя зарекомендовали детерминантные гибриды $\mathrm{F}_{1}$ Донской (рис. 5) и $F_{1}$ Пламенный (рис. 6), а из индетерминантных - гибриды $F_{1}$ Пегас (рис. 7), $F_{1}$ Армада (рис. 8) и $\mathrm{F}_{1}$ Огневский. Эти гибриды имеют разные сроки созревания, форму и размер плода, но успешно произрастают как в обогреваемых, так и в необогреваемых весенних теплицах, сочетая высокую урожайность, товарность с устойчивостью к перегревам, комплексу болезней в почвенной культуре. В хозяйствах, специализирующихся на получении розовоплодных томатов, предлагаются к выращиванию на юге России гибриды индетерминантного типа с укороченными

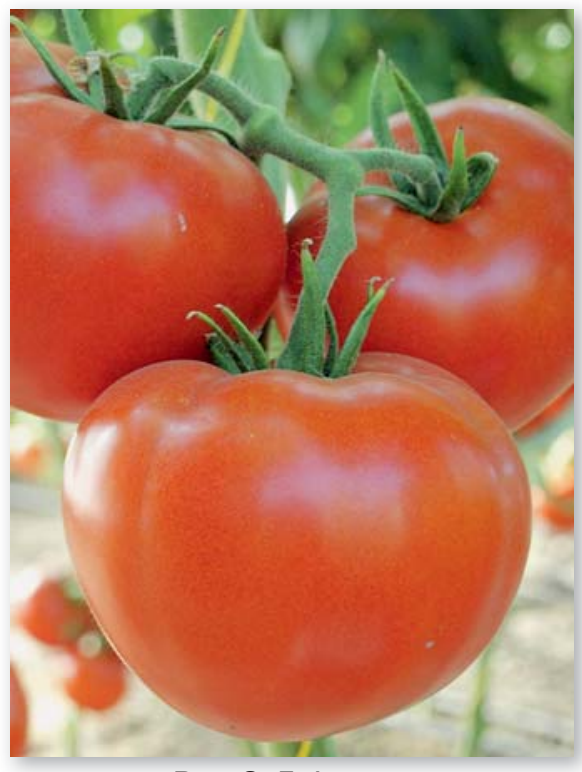

Рис. 8. $F_{1}$ Армада междоузлиями: $F_{1}$ Розовый фрегат (рис.9), $F_{1}$ Розовый носик (рис.10), $F_{1}$ Сударь, $F_{1}$ Боярин и перспективный гибрид 7/18 с малиновыми плодами. Наряду с отличными вкусовыми качествами эти гибриды имеют высокую транспортабельность и продолжительный срок хранения. Особенно это касается гибрида $F_{1}$ Розовый фрегат, лежкость которого достигает одного месяца в нерегулируемых условиях. Плоды этого гибрида выдерживают длительную транспортировку. В группе гибридов для весенних теплиц в ближайшее время появятся желтоплодные детерминантные и индетерминантные гибриды. Ждет пополнения и наш индетерминантный гибрид типа Кумато - $F_{1}$ Креолка, уже имеющий своих поклонников. Это уникальные образцы, способные накапливать в плодах наряду с каротиноидами и Р-активные вещества, которых в обычных сортах очень мало.

Для хозяйств, производящих продукцию для промышленной переработки, ведется самостоятельная селекционная программа. И если ранее основное внимание уделялось созданию свободноопыляющихся сортов, дающих более дешевое сырье, таких, как Аделина, Розовый агат, Красный банкир, то в последние годы и здесь создаются гибриды, что связано с освоением в товарных хозяйствах кассетных технологий производства рассады, позволяющих сократить потребность в семенах, но повысивших требования к их качеству. Первенец здесь - гибрид $\mathrm{F}_{1}$ Бемби с компактным габитусом

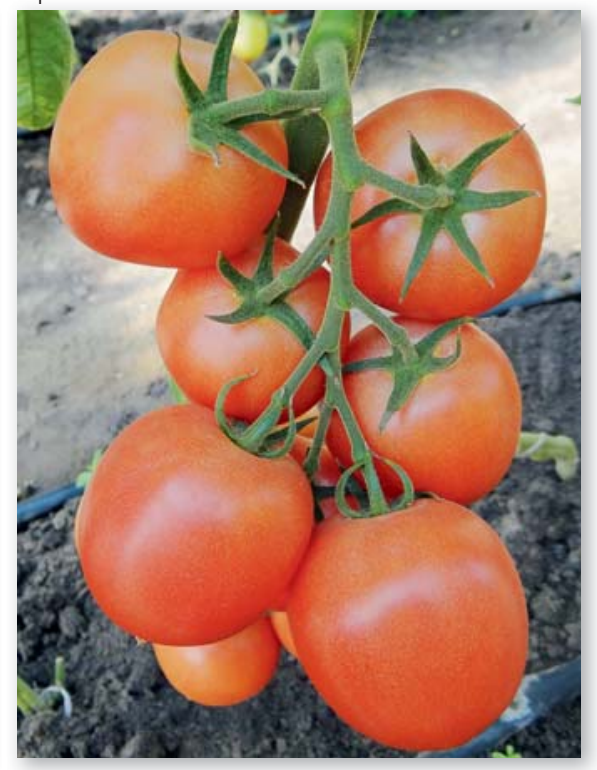

Рис. 9. $F_{1}$ Розовый фрегат 
и мелкими порционными плотными плодами, пригодными для цельноплодного консервирования в мелкой таре.

Наряду с созданием сортимента томата для юга России постоянно проводятся исследования по совершенствованию технологий возделывания в открытом грунте и весенних теплицах. Сегодня большое внимание уделяется разработке систем формировки и полумеханизированной подвязки растений томата с различным типом роста, что позволяет экономить трудовые ресурсы, затраты на которые существенно выросли в последние годы. Проводится изучение биометода защиты растений в весенних теплицах, совершенствование систем минерального питания при поливах минерализованной водой и возделывании на грунтах.

Создание сортимента томата для юга России и научное сопровождение освоения новых сортов и гибридов являются приоритетной задачей работы южного селекцентра Агрохолдинга «Поиск» на перспективу. В постоянном режиме его сотрудники консультируют товаропроизводителей, демонстрируют новые сорта и гибриды как на базе самого селекцентра, так и в хозяйствах разных зон на юге России. Активно используют в качестве демонстрационных площадок и крупные региональные мероприятия: Дни поля, агропромышленные выставки. Используют возможности интернета и печатных изданий, других средств массовой информации. Эта работа будет усиливаться и совершенствоваться.

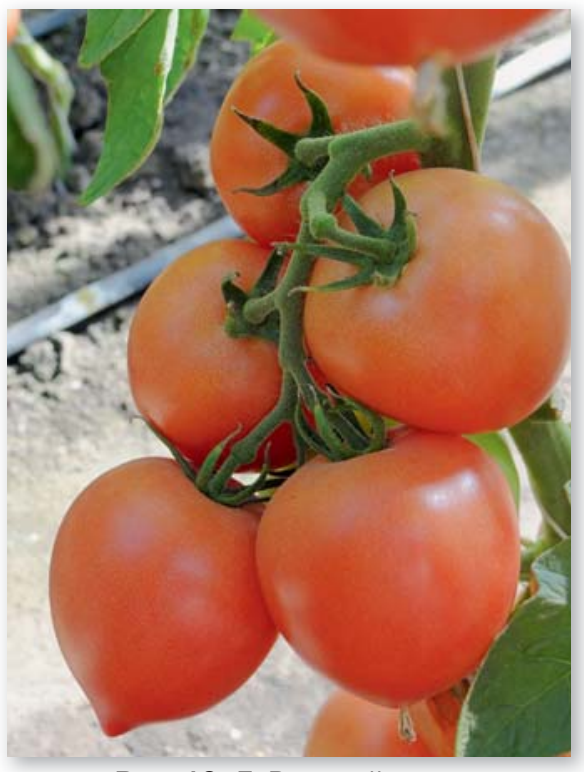

Рис. 10. $F$ Розовый носик
Таким образом, конкурентоспособная отечественная селекция томата существует, и она способна произвести полноценное импортозамещение, о чем свидетельствует деятельность одной из ведущих российских селекционно-семеноводческих компаний - Агрохолдинга «Поиск» на юге России.

\section{Библиографический список}

1.Василенко В.Н. Овощеводство Ростовской области: проблемы и решения // Картофель и овощи. 2013. №7. C. $2-4$

2.Клименко Н.Н. Овощеводство юга России // Картофель и овощи. 2013.№8. С. 2-4.

3.Малько А.М. Мировой рынок семян и место России в нем // Картофель и овощи. 2013. №4. С. 2-4.

4.Резвый Г.И. Семеноводство и его понимание на современном этапе // Картофель и овощи. 2018. №7. C. 2-15.

5. Огнев В.В., Терешонкова Т.А., Ховрин А.Н. Томаты для юга: потребности рынка и ответы отечественной селекции // Картофель и овощи. 2017. №11. С. 34-36.

6.Редичкина Т., Артемьева Г. Эксклюзив из теплицы // Вестник овощевода. 2018. №10. С. 7-9.

7.Клименко Н.Н., Ховрин А.Н., Огнев В.В. Агрохолдинг «Поиск». Селекция здоровья и долголетия // Картофель и овощи. 2017. №9. С. 8-10.

8.Анализ импорта огурцов и томатов в РФ: итоги и тенденции // Гавриш. 2018. №5. С. 24-28.

9.Мирошниченко Д. Обзор рынка: овощеводство [электронный ресурс] URL: https://www.openbusiness. ru/biz/business/obzor-rynka-ovoshchevodstvo/ Дата обращения 29.09. 2019.

10.Гаспарян Ш.В., Масловский С.А. Переработка овощей в России: настоящее и будущее // Картофель и овощи. 2018. №6. С. 2-6.

\section{Об авторах}

Чернова Татьяна Викторовна, селекционер ССЦ «Ростовский» Агрохолдинга «Поиск»

Огнев Валерий Владимирович, канд. с.-х. наук, доцент, директор ССЦ «Ростовский» Агрохолдинга «Поиск». E-mail: ognevvv@bk.ru Корсунов Евгений Иванович, аспи рант Донского государственного аграрного университета

Tomatoes in southern Russia

T.V. Chernova, breeder, Rostov Breeding

Centre of Poisk Agro holding

V.V. Ognev, PhD, associate professor, director, Rostov Breeding Centre of Poisk Agro holding. E-mail: ognevvv@bk.ru E.I. Korsunov, postgraduate student, Don State Agrarian University

Summary. An analysis of the importance of vegetable crops on the example of tomato in southern Russia is given. The contribution of the Poisk Agro holding in the creation of tomato variety for southern Russia is shown. Prospects for the breeding of new domestic hybrids of tomato with high consumer qualities are determined.

Keywords: vegetables, tomato, selection, variety, technology, import substitution.

\section{Семена Агрохолдинга «Поиск» в органическом
производстве}

Агрохолдинг «Поиск» и кооператив «Союз органических фермеров Кубани» успешно провели опыт первого применения семян крупнейшей российской селекционно-семеноводческой компании в органическом земледелии.

В рамках сотрудничества Агрохолдинг предоставил члену кооператива, хозяйству «Биоферма Кубани», сертифицированному по европейскому органическому стандарту, семена, не обработанные фунгицидами, которые были согласованы немецким сертификационным центpom CFERES для применения в органическом обороте. К сортам и гибридам в органическом производстве применяются особые требования - они должны обладать повышенной устойчивостью к заболеваниям, иметь высокую потенциальную урожайность, поскольку удобрения здесь применяют только органические. В первую очередь, были использованы семена тепличных томатов, огурца и томатов-черри для весеннего оборота в органических теплицах хозяйства. Сегодня можно подвести первые итоги применения семян: гибрид $F_{1}$ Пилигрим продемонстрировал высокое качество урожая в весеннем обороте, прекрасные товарные характеристики, на уровне лучших голландских гибридов. Органическую продукцию огурца гибрида $F_{1}$ Пилигрим уже с апреля поставляют потребителям Москвы и Санкт-Петербурга. Гибрид томата $F_{1}$ Сударь прекрасно отреагировал на органическую схему питания и защиты, плоды на первой кисти достигали массы 400 г. Гибриды томатов-черри $\mathrm{F}_{1}$ Волшебная арфа и $\mathrm{F}_{1}$ Сладкий фонтан также демонстрируют хорошую урожайность и особенно радуют потребителей органической продукции своими вкусовыми качествами - сладкие и ароматные маленькие плоды пользуются особым спросом.

С.А. Воданюк, председатель СППСК “Союз органических фермеров Кубани», основатель органического хозяйства «Биоферма Кубани» 